\title{
金矮生苹果叶片气体交换参数对土壤水分的响应
}

\author{
张光灿 ${ }^{1}$ 刘 霞 $^{1 *} \quad$ 贺康宁 $^{2}$ 王百田 $^{2}$ \\ （1 山东农业大学林学院, 泰安 271018）（2 北京林业大学资源与环境学院, 北京 100083)
}

摘 要 在黄土高原半干旱地区, 通过测定 10 年生金矮生苹果 (Malus pumila cv. Goldspur) 叶片气体交换参数与土 壤水分的定量关系, 探讨了土壤水分胁迫对光合作用的影响规律, 以确定苹果园节水灌溉适宜的土壤水分调控标 准。结果表明 旪片的净光合速率 $\left(P_{n}\right)$ 、蒸腾速率 $\left(T_{r}\right)$ 、水分利用效率 $(W U E)$ 、气孔导度 $\left(G_{s}\right)$ 、细胞间隙 $\mathrm{CO}_{2}$ 浓度 $\left(C_{i}\right)$ 和气孔限制值 $\left(L_{s}\right)$ 对土壤水分的变化具有明显不同的阈值反应。土壤含水量 $(S W C)$ 大约在田间持水量的 $60 \% \sim 86 \%$ 范围内, $P_{n}$ 和 $T_{r}$ 均保持较高的水平，小于田间持水量的 $60 \% \sim 86 \%$ 后, 两者均随土壤湿度的减少而明 显下降。维持较高叶片水分利用效率( WUE) 的 $S W C$ 约在田间持水量的 $50 \% \sim 71 \%$ 左右。当 $S W C$ 小于田间持水量 的 $48 \%$ 以后, $G_{s}$ 和 $L_{s}$ 明显降低, 而 $C_{i}$ 急剧增加, 水分胁迫条件开始直接作用于叶肉细胞, 导致光合速率下降, 由气 孔限制因素转变为非气孔因素。据此我们认为: 在半干旱黄土高原地区, 金矮生苹果园节水灌溉适宜的 $S W C$ 范围 大约在田间持水量的 50\% 71\%左右，所允许的土壤水分亏缺程度为田间持水量的 $48 \%$ 左右。

关键词 金矮生苹果 光合速率 蒸腾速率 水分利用效率 土壤含水量

\section{RESPONSES OF GAS EXCHANGE PARAMETERS OF GOLDSPUR APPLE TREE TO SOIL WATER VARIATION}

\author{
ZHANG Guang-Can ${ }^{1}$ LIU Xia ${ }^{1 *}$ HE Kang-Ning ${ }^{2}$ and WANG Bai-Tian ${ }^{2}$ \\ (1 Shandong Agricultural University, Taian, Shandong 271018, China) \\ (2 Beijing Forestry University, Beijing 100083 , China)
}

\begin{abstract}
Goldspur Apple (Malus pumila cv. Goldspur) is one of the main fruit trees planted on the Loess Plateau in a semi-arid region. Gas exchange parameters in leaves of ten-year-old trees were studied under different soil water conditions with a LI-6200 portable photosynthesis system and a LI-1600 portable steady state porometer, in order to explore the effects of soil water stress on the photosynthesis and the suitable soil water content $(S W C)$ for water-saving irrigation of the apple orchard.
\end{abstract}

The experimental site is located in Tuqiaogou watersheds, Yukou town, Fangshan county, Shanxi province , China , a part of a gully-hilly area of Loess Plateau in the middle reaches of the Yellow River. It lies at $37^{\circ} 36^{\prime} 58^{\prime \prime} \mathrm{N}, 110^{\circ} 02^{\prime} 55^{\prime \prime} \mathrm{E}$, with an average altitude of about $1200 \mathrm{~m}$ and a maximum altitude of 1446 $\mathrm{m}$. The average annual precipitation is $416.0 \mathrm{~mm}$, with the precipitation in June , July , August and September being more than $70 \%$ of the total amount. Annual potential evaporation is $1857.7 \mathrm{~mm}$ and the greatest evaporation occurs in April to June. The soil belongs to medium soil and lossal soil and the average soil bulk density is about $1.2 \mathrm{~g} \mathrm{~cm}^{-3}$, and mean field capacity $(F C)$ is approximately $21.0 \%$. In the study on responses of gas exchange parameters to soil water, eighteen apple trees were selected as experimental samples and divided into six groups (three trees per group and signed by I , II , III , IV , V and VI). The soil water gradient was obtained in six groups by providing different water supply. During soil water treatment, $S W C$ measured with LNW-50A neutron probe on June 12 , June 16 and June 20,1999 were as follows : group I (22.4\% , $18.7 \%$ and $16.7 \%)$, II $(20.1 \%, 17.4 \%$ and $16.2 \%)$, III $(18.2 \%, 16.7 \%$ and $14.8 \%)$, IV $(15.9 \%, 13.6 \%$ and $11.9 \%), \mathrm{V}(11.7 \%, 10.5 \%$ and $9.6 \%)$ and VI $(6.2 \%, 5.6 \%$ and $5.0 \%)$.

A LI-6200 portable photosynthesis system was used to measure the photosynthesis parameters including photosynthetic rate $\left(P_{n}\right)$, stomatal conductance $\left(G_{s}\right)$ and intercellular $\mathrm{CO}_{2}$ concentration $\left(C_{i}\right)$, while at the same time transpiration rate $\left(T_{r}\right)$ was measured with a LI-1600 portable steady state porometer. The water use efficiency $(W U E)$ and stomatal limiting value $\left(L_{s}\right)$ were calculated according to formula $W U E=P_{n} / T_{r}$ and $L_{s}=1-C_{i} / C_{a}$. These gas exchange parameters were measured on the same day that $S W C$ was observed on June 12 , June 16 and June 20,1999 , and the duration of observation was at 9:00-11:00 am each time.

The results showed that when $S W C$ was within a range about $60 \%-86 \%$ of field capacity $(F C), P_{n}$ 
and $T_{r}$ were maintained in a relative steady state and higher level , but below $60 \%-86 \%$ of $F C$, both $P_{n}$ and $T_{r}$ decreased obviously with decreasing soil moisture. The $S W C$ range to support $W U E$ at a relative steady state and higher level was about $50 \%-71 \%$ of $F C$. When $S W C$ was less than $48 \%$ of $F C, G_{s}$ and $L_{s}$ declined with decreasing of soil moisture, while $C_{i}$ increased rapidly. Based on the analysis of stomatal limitation of photosynthesis using two criteria $\left(C_{i}\right.$ and $\left.L_{s}\right)$ suggested by Farquhar and Sharkey, it implied that the predominant cause of restricting $P_{n}$ had turn into non-stomatal limitation under severe water stress. According to the main intention of water-saving irrigation for enhancing water use efficiency, it is concluded that the suitable range of $S W C$ was about $50 \%-71 \%$ of $F C$, as the most severe degree of soil water stress tolerated for photosynthesis was about $48 \%$ of $F C$.

Key words Goldspur apple tree , Net photosynthesis rate , Transpiration rate , Water use efficiency , Soil water content

在我国广大的北方地区，干旱缺水是最突出的 生态特征,也是制约植被恢复与农林业生产最为关 键的生态因子。随着水资源危机和干旱化危害的不 断加剧, 节水农业生产模式的发展日益重要。如何 充分提高有限水资源的有效利用率和生产效率，并 创造出有利于农业可持续发展的生态环境是节水农 业研究的核心和最终目标(王会肖等, 2000;李合生， 2001 ）植物光合作用与水分代谢及其生理生态机理 是节水农业重要的理论基础,如何调控土壤水分才 能在最大限度减少用水的条件下形成植物产量和水 分利用效率的最佳组合是节水灌溉研究的关键和热 点问题（山仑等,1991;刘文兆,1998)。关于节水灌 溉及其生理生态基础的研究在农作物上较多(山仑, 1993 ;山仑等，1998; 黄占斌等，1997），涉及水分胁迫 对作物光合作用及水分利用效率的影响及其机理方 面的研究比较深入 (景芯莲,1999)。研究认为, 作物 有一种缺水效应, 对有限缺水有一定的适应性和抵 抗性（马忠明，1998）; 在适度水分胁迫下，光合作用 不但没有受到影响，甚至高于充足供水的植株，作物 产量不一定明显降低, 水分利用效率却显著提高(张 喜英等,2000 魏虹等, 2000)。作物受旱后, 光合作 用受抑制的主要原因都有从气孔因素 (轻度及中度 水分胁迫) 向非气孔因素 (中度以上和严重水分胁 迫)转变的过程, 其转变时间因作物的抗旱能力、干 旱程度及施加方式等因素而异 (Farquhar \& Sharkey , 1982 , 许大全 ,1997 沈允钢, 1998)。

苹果是中国的第一大果树，在中国北方地区的 农业发展和果树生产中占有重要地位。近年来在旱 作与节水栽培技术及其生理和生长效应方面的研究 取得了一些成果(徐呈祥等,2000 张立新等,2001)， 但与农作物相比, 有关节水灌溉的生理生态机制研 究, 尤其是光合作用与土壤水分关系的研究还处于 起步阶段(徐呈祥等,2000)。已有的报道大都是盆 栽试验的结果且缺乏多级水分胁迫梯度的观测 (李
岩等,1998; 曹慧等,2000;曲桂敏等,2000; 接玉玲 等 2001）应用于指导实际生产受到较大限制。中 国虽然在苹果生产的土壤水分管理中强调 前促后 控，促控结合”、春水早，夏水巧 秋水控，冬水饱”的 节水灌溉思想, 但是还远未达到数量化、指标化的地 步(徐呈祥等, 2000)。因此, 需要进一步探索田间环 境条件下土壤水分对苹果光合作用的影响规律，明 确有利于促进光合作用和提高水分利用效率的土壤 水分供给水平 (适度水分胁迫程度)。本文以黄土高 原半干旱区苹果园 10 年生的金矮生苹果 (Malus pumila cv. Goldspur) 为对象, 研究其光合作用和水分 利用效率随土壤水分的连续变化规律, 以期为苹果 树旱作栽培与节水灌溉的田间水分管理提供理论依 据和技术标准。

\section{1 材料和方法}

\section{1 试验地概况}

试验地设在山西省方山县峪口镇土桥沟流域 (北京林业大学 径流林业”试验研究基地) 地处 $37^{\circ}$ $36^{\prime} 58^{\prime \prime} \mathrm{N}, 110^{\circ} 02^{\prime} 55^{\prime \prime} \mathrm{E}$, 属于黄河中游半干旱黄土 丘陵沟壑区。试验区海拔高度 $1200 \mathrm{~m}$ 。年平均降 水量 $416.0 \mathrm{~mm}, 6 \sim 9$ 月降水占全年的 $70 \%$ 以上;年 平均蒸发量达 $1857.7 \mathrm{~mm}$, 最大蒸发量在 $4 \sim 6$ 月。 年平均气温 $7.3{ }^{\circ} \mathrm{C}$, 极端最高温度 $35.6{ }^{\circ} \mathrm{C}$, 极端最 低温度 $-25.3{ }^{\circ} \mathrm{C}$, 年无霜期 $140 \mathrm{~d}$ 。土壤为黄绵土， 质地为中壤土, $\mathrm{pH}$ 值为 $8.0 \sim 8.4$; 属于森林草原灌 丛植被区。

试验地土壤平均容重 (Soil bulk density) 为 $1.2 \mathrm{~g}$ $\mathrm{cm}^{-3}$,田间持水量 (Field capacity, $F C$ ) 为 $21.0 \%$ 左 右。

\section{2 试验材料与处理}

在苹果园中选取生长健壮的 10 年生金矮生苹 果树 18 株, 将其分为 6 组 (分别记为第 I、II、III、 $I V 、 V 、 V I$ 组), 每 3 株为 1 组。在每一植株附近 (离 
树干约 $0.5 \mathrm{~m}$ 处) 各埋设 1 根长度为 $1 \mathrm{~m}$ 的土壤中 子水分仪测定铝管。在不同处理之间挖一条深约 1 $\mathrm{m}$ 、宽约 $0.2 \mathrm{~m}$ 的隔水沟，以防止不同处理之间土壤 水分相互渗透的影响。各组处理之间通过人为给水 和自然耗水产生多级土壤水分梯度。具体方法是： 首先在各试验植株周围 (半径约 $1 \mathrm{~m}$ ) 将土壤表面修 成内低外高的坡面，外围修筑高约 $0.2 \mathrm{~m}$ 的挡水土 埂。试验观测两天前 (1999 年 6 月 10 日)，用水桶分 别对各组植株实施不同的灌水量，用土壤中子水分 仪监测土壤含水量 (Soil water content ; $S W C$ ) 的变化。 两天后获得初期水分梯度并进行第一次测定 (时间 为 1999 年 6 月 12 日), 各组处理的 $S W C$ (3 株平均 值) 为: I $(22.4 \%) 、$ II $(20.1 \%) 、$ III $(18.2 \%) 、$ IV $(15.9 \%) 、 V(11.7 \%)$ 和 VI $(6.2 \%)$ 。然后每隔 $3 \mathrm{~d}$ 通过自然蒸发耗水进一步产生连续变化的土壤水分 胁迫程度后，再进行第二次和第三次测定(时间分别 为 1999 年 6 月 16 日和 20 日)。第二和第三次测定 时各组处理的 $S W C$ (3 株平均值) 为 : I (18.7\% 和 $16.7 \%) 、 I I(17.4 \%$ 和 $16.2 \%) 、 I I I(16.7 \%$ 和 $14.8 \%) 、 \mathrm{~V}(13.6 \%$ 和 $11.9 \%) 、 \mathrm{~V}(10.5 \%$ 和 $9.6 \%)$ 和 VI ( $5.6 \%$ 和 $5.0 \%$ )。另外选一组 (3 株) 为对照 (不 供水),3 次测定时的 $S W C$ (3 株平均值) 分别为 $5.0 \% 、 4.8 \%$ 和 $4.7 \%$ 。

\section{3 试验观测方法}

用 LI-6200 (USA) 便携式光合仪 (Portable photosynthesis system) 测定光合作用参数, 其中, 叶片净光 合速率 (Net photosynthesis rate, $P_{n} ; \mu \operatorname{molCO}{ }_{2} \cdot \mathrm{m}^{-2}$. $\mathrm{s}^{-1}$ )、胞间 $\mathrm{CO}_{2}$ 浓度 (Intercellular $\mathrm{CO}_{2}$ concentration， $C_{i} ; \mu \mathrm{mol} \mathrm{mol}^{-1}$ )、气孔导度 (Stomatal conductance, $G_{s}$; $\mathrm{cm} \mathrm{s}^{-1}$ ) 等由光合仪直接输出。蒸腾速率 (Transpira-

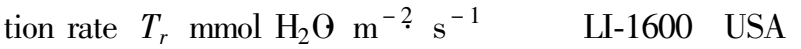
便携式稳态气孔计(Portable steady state porometer)测 定 (与光合作用观测同步进行)。气孔限制值 (Stomatal limiting value, $\left.L_{s} ; \%\right)$ 和叶片瞬时水分利用效率 (Water use efficiency of leaf, WUE ; $\mu \mathrm{mol} \mathrm{CO}_{2} \mathrm{mmol}^{-1}$ $\mathrm{H}_{2} \mathrm{O}$ ) 由公式计算 即 $L_{s}=1-C_{i} / C_{a}$ (Berry \& Dowton , $1982) ; W U E=P_{n} / T_{r}$ (王会肖等 2000$)$ 。由于气孔计 测定的蒸腾速率高于自然蒸腾值, 并且水分环境条 件越好, 误差越大, 所以用快速称重法对气孔计的观 测值进行了适度校正(刘奉觉, 1997)。

每次测定时分别在树冠东、西、南、北方向的中 部各选取 5 个健康叶片 (每株树观测 20 个叶片, 每 组处理共观测 60 个叶片) ,并做好标记，在不同时间
观测时皆用同一叶片,3 次重复读数。土壤水分处 理与观测期为 1999 年 6 月 $10 \sim 20$ 日，第一次测定 (1999 年 6 月 12 日) 在人工给水 $48 \mathrm{~h}$ 后进行, 以后 每隔 $3 d$ 分别进行第二次 (1999 年 6 月 16 日)和第 三次 (1999 年 6 月 20 日) 观测。3 次观测均为晴天， 具体时间为 9:00 11:00。

土壤含水量 $(S W C)$ 测定用 $\mathrm{LNW}-50 \mathrm{~A}$ 型土壤中 子水分仪 (Neutron probe)，与光合作用观测同日进 行, 观测深度为 $1.0 \mathrm{~m}$ (每 $20 \mathrm{~cm}$ 一层 取平均值)。

文中的 $S W C$ 为质量含水量 (Mass water content, $M W C ; \%$ )，相对含水量 ( Relative water content, $R W C ; \%)$ 为 $S W C$ 与田间持水量 $(F C)$ 的比值。

\section{4 数据处理}

将不同土壤水分含量处理、不同观测时间 (3 次 观测) 测定的土壤含水量 $(S W C)$ 和叶片气体交换参 数的数据集中处理, 数据的统计计算和回归分析应 用 SPSS (Statistical Program for Social Science) 软件。 获得叶片气体交换参数 $\left(P_{n} 、 T_{r} 、 W U E 、 G_{s} 、 C_{i} 、 L_{s}\right)$ 对 土壤水分 $(S W C$ ) 的响应规律(图 1 和图 2)。

\section{2 结 果}

\section{1 净光合速率和蒸腾速率对土壤水分的响应}

随着土壤含水量 $(S W C)$ 增加, 苹果叶片净光合 速率 $\left(P_{n}\right)$ 和蒸腾速率 $\left(T_{r}\right)$ 上升较快, $S W C$ 增加到一 定临界值以后, $P_{n}$ 和 $T_{r}$ 由上升变为下降, 表现为对 土壤水分具有明显的阈值反应 (图 $1 \mathrm{a} 、 \mathrm{~b}$ )。 $S W C$ 大 约在 $12.5 \% \sim 18.0 \%$ (相当于土壤田间持水量的 $60 \% \sim 86 \%$, 记为 $R W C)$ 范围内, $P_{n}$ 和 $T_{r}$ 相对稳定 在较高水平上, 并不随土壤水分的增加而明显变化, 表明此土壤水分國值对 $P_{n}$ 和 $T_{r}$ 具有较高的和基本 相同的有效性。

$P_{n}$ 与 $S W C$ 的关系曲线符合二次方程 (图 1a), 由此确定出 $P_{n}$ 最高时的 $S W C$ 临界值大约为 $16.0 \%$ $(R W C$ 为 $76 \%)$, 表明 $S W C$ 在 $16.0 \%$ 左右是苹果叶 片光合作用有效性最高的土壤水分。 $T_{r}$ 与 $S W C$ 的 关系曲线符合三次方程 (图 $1 \mathrm{~b}$ ), 由此确定出 $T_{r}$ 最 高的 $S W C$ 临界值大约为 $17.0 \%$ ( $R W C$ 为 $81 \%$ ）, 即 此土壤水分对苹果叶片蒸腾作用的有效性最高。

\section{2 叶片水分利用效率对土壤水分的响应}

叶片水分利用效率 (WUE) 取决于 $P_{n}$ 与 $T_{r}$ 的比 值。从图 1c 可以看出, 随着 $S W C$ 的增加, $W U E$ 表 现出近似 $S$ ”形的变化规律 :即 $S W C$ 大约在小于 $10.5 \%$ 的范围内, WUE增加较快; $S W C$ 在 $10.5 \%$ 

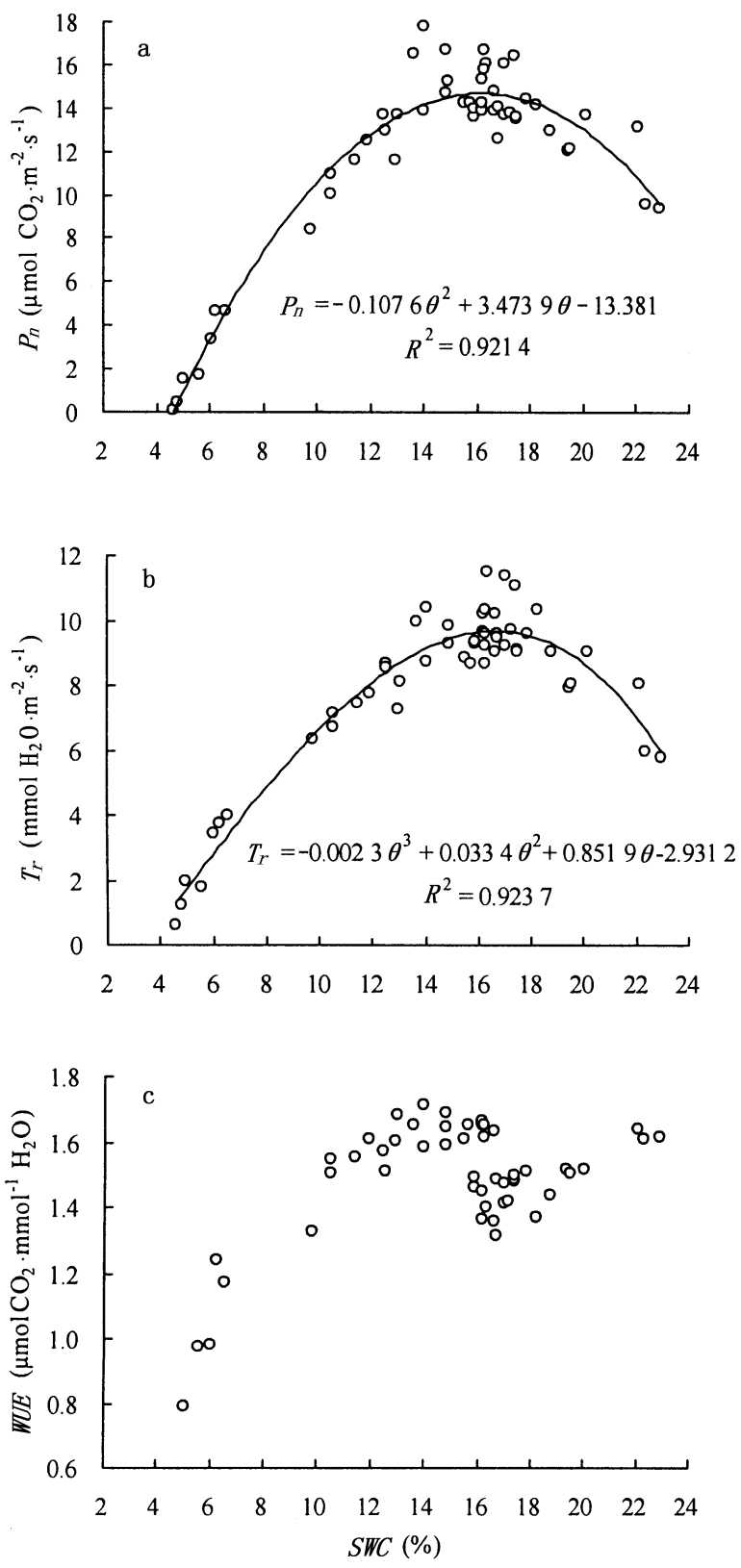

图 1 苹果叶片的 $P_{n}, T_{r}$ 和 $W U E$ 对 $S W C$ 的响应

Fig. 1 Responses of $P_{n}, T_{r}$ and $W U E$ in apple leaves to $S W C$

$P_{n}$ 浄光合速率 Net photosynthetic rate $T_{r}$ 蒸腾速率 Transpiration rate $W U E$ 旪片水分利用效率 Water use efficiency $S W C$ :土壤含水 量 Soil water content

$15.0 \%(R W C$ 在 $50 \% \sim 71 \%)$ 的范围内, $W U E$ 一直 维持较高的水平而且变化不大，表明此土壤水分阈 值对 $W U E$ 具有较高的和基本相同的有效性; 而 $S W C$ 大于 $15.0 \%$ 左右以后, WUE 随土壤水分的增 加反而下降, 当 $S W C$ 大约在 $17 \%(R W C$ 在 $81 \%)$ 时, $W U E$ 出现较小值。

2.3 气孔导度、气孔限制值和胞间 $\mathrm{CO}_{2}$ 浓度对土壤 水分的响应

叶片气孔导度 $\left(G_{s}\right) 、 气 孔$ 限制值 $\left(L_{s}\right)$ 和胞间
$\mathrm{CO}_{2}$ 浓度 $\left(C_{i}\right)$ 对不同國值的土壤水分具有不同的响 应规律 (图 2)。 $S W C$ 大约在 $10.0 \% \sim 16.0 \%$ ( $R W C$ 在 $48 \% \sim 76 \%$ ) 范围内, 随着土壤湿度的降低, $G_{s}$ 和 $C_{i}$ 明显下降 (图 2a、b) ,但 $L_{s}$ 明显上升 (图 2c) 。当 $S W C$ 小于 $10.0 \%$ 以后, 随着土壤水分降低, $G_{s}$ 和 $L_{s}$ 明显下降(图 2a、b) , 而 $C_{i}$ 显著上升(图 2c)。这表明 随着土壤水分胁迫的加剧, 叶片 $P_{n}$ 下降 (图 1a) 的主 要原因与气孔因素向非气孔因素转变 (Farquhar \& Sharkey, 1982 许大全, 1997) 有关, 发生转变的土壤水 分临界值大约在 $S W C$ 为 $10.0 \%$ ( $R W C$ 为 $48 \%$ ) 左右。
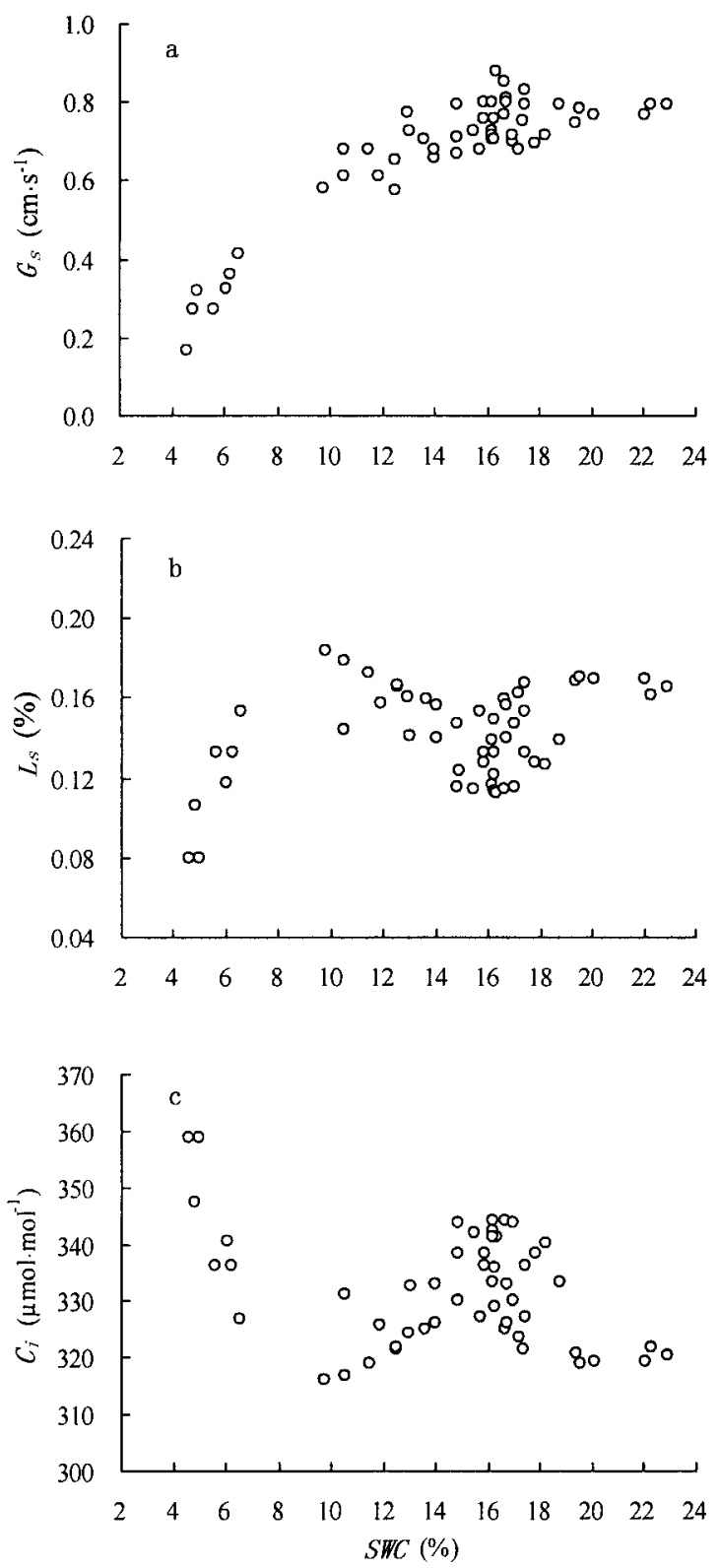

图 2 苹果叶片的 $C_{i}, L_{s}$ 和 $G_{s}$ 对 $S W C$ 的响应

Fig.2 Response of $C_{i}, L_{s}$ and $G_{s}$ in apple leaves to $S W C$

$C_{i}$ 胞间 $\mathrm{CO}_{2}$ 浓度 Intercellular $\mathrm{CO}_{2}$ concentration $L_{s}$ :气孔限制值 Stomatal limitation $G_{s}$ 气孔导度 Stomatal conductance $S W C$ : 土壤含水 量 Soil water content 


\section{3 讨 论}

植物的生长发育状态及各种生理活动与水分有 着密切联系。土壤水分对植物生长的影响有一个最 高、最适和最低的基点。低于最低点植物生长停止， 甚至枯死; 高于最高点, 根系缺氧, 窒息发育不良甚 至整个植株死亡; 只有处于最适范围, 才能维持植物 的水分平衡，保证植物良好生长和发育(李合生， 2001)。

植物各种生理活动对土壤水分的响应并不一 致, 大多数植物生长的最适含水量较高 蒸腾的最适 土壤含水量较低, 而同化所需最适含水量更低。对 农作物的研究表明, 当土壤有效水分减少时, 与作物 产量形成有密切关系的几个生理过程都会受到水分 亏缺的影响, 按受影响程度和先后排序为生长-蒸腾 -光合-运输(山仑等,1998)。水分亏缺对生长的影 响, 主要原因是减弱细胞扩张, 首先导致光合绿色面 积减小。蒸腾则是作物吸水、生长过程中伴随的生 理现象，对产量形成并无直接关系。水分亏缺对光 合作用与运输的影响才有实质性作用, 因为光合作 用是作物体中有机物质形成的唯一过程, 这一过程 中水又是光合作用形成有机物质的重要原料, 水对 光合作用直至产量形成的影响是决定产量有否的问 题; 而生长、蒸腾、运输过程对产量的影响是决定产 量多少的问题。显然前者更为重要更为直接, 因而 在分析合理土壤水分指标时, 常以影响光合作用的 土壤水分指标为主 称之为光合土壤水分指标(陈玉 民等, 1997)。综合对农作物的研究结果, 玉米、冬小 麦等光合作用适宜的土壤水分阈值大约在 $R W C$ 为 60\%～80\%之间(杨文斌等，1997）, 这一指标略低于 生长、蒸腾适宜的土壤水分指标。从本研究结果看 (图 1a) 维持苹果叶片较高 $P_{n}$ 的土壤水分國值大 约在 $R W C$ 为 $60 \% \sim 86 \%(S W C$ 为 $12.5 \% \sim 18 \%$ )之 间 其中对光合作用最适宜的土壤水分在 $R W C$ 为 $76 \%(S W C$ 为 $16 \%$ ) 左右，与农作物的光合土壤水分 指标基本相同。在此土壤水分范围内, 苹果叶片的 $T_{r}$ 同样处于较高水平 (图 $1 \mathrm{~b}$ ), $T_{r}$ 最高时的土壤水 分在 $R W C$ 为 $81 \%(S W C$ 为 $17.0 \%$ ) 左右。因而在此 土壤水分范围内, 苹果叶片的 WUE 并非一直维持 在较高水平(图 1c) ,尤其是 $R W C$ 大于 $71 \%$ ( $S W C$ 大 于 $15.0 \%$ ) 以后, 随土壤水分增加和 $T_{r}$ 的提高 $W U E$ 反而下降，当 $S W C$ 大约为 $17 \%(R W C$ 为 $81 \%$ ) 时， WUE 出现低谷值, 这恰恰是 $T_{r}$ 最高时的土壤水分。 表明较高的土壤水分 ( $R W C$ 大于 $71 \%$ 以后) 虽然有
利于苹果 $P_{n}$ 和产量的提高, 但同时导致高 $T_{r}$ 使水 分消耗量较大，不利于 WUE 的提高，这显然不符合 干旱缺水地区农业以高效利用有限水资源为目标的 土壤水分管理标准。

尽可能提高对自然降水和灌溉水的 $W U E$, 同时 兼有较高的产量是节水农业田间水分管理的核心 (山仑等, 1998 张喜英等,2000)。作物-水分关系的 研究表明, 作物对土壤有限缺水有一定的适应性和 抵抗性(马忠明,1998)。在适度的土壤水分胁迫范 围内, 随着 $G_{s}$ 的适度减小, $T_{r}$ 与 $P_{n}$ 均下降, 但由于 蒸腾作用对水分胁迫的响应比光合作用敏感, 蒸腾 作用超前于光合作用下降, $T_{r}$ 的下降速率大于 $P_{n}$ 的下降速率, WUE 反而提高。 $P_{n}$ 降低并不明显, 作 物仍可获得较高或中等以上的产量, 故这种适度土 壤水分胁迫被称为使 $W U E$ 与产量协调一致的土壤 水分(马忠明,1998; 景芯莲,1999)。农作物这一适 宜的土壤水分阈值大约在 $R W C$ 为 $40 \% \sim 60 \%$ 之间 (黄占斌,1998)。本研究表明, 维持苹果较高 WUE 的土壤水分阈值在 $R W C$ 为 $50 \% \sim 71 \%(S W C$ 为 10.5\% 15.0\%) 之间, 大于和小于此土壤水分范围 时, WUE 都明显下降(图 1c)。

综合上述讨论我们认为，在半干旱黄土高原地 区,金矮生苹果园节水灌溉适宜的 $R W C$ 应控制在 60\% 71\%（SWC 在 $12.5 \% １ 5.0 \%$ )之间, 此土壤 水分阈值以维持较高 $P_{n}$ 的最低 $S W C$ 为下限, 以维 持较高 $W U E$ 的最高 $S W C$ 为上限, 能保证苹果叶片 同时获得最大的 $W U E$ 和较高的 $P_{n}$, 是使 $W U E$ 与产 量协调一致的土壤水分阈值或 经济水阈值” (山仑 等, 1991)。比较其它的研究, 在盆栽试验条件下得 出, 2 年生金矮生苹果节水灌溉适宜的土壤水分在 $R W C$ 为 $55 \% \sim 75 \%$ 之间 (王克勤等，2002）；其它品 种的苹果树在 $R W C$ 为 $60 \% \sim 80 \%$ 之间果实产量最 高和品质最好(王文元,1988)，与本研究结果有所差 别。这说明节水灌溉适宜的土壤水分指标与苹果树 的品种及年龄有关，不能一概而论。另外可以看出， 苹果节水灌溉适宜的土壤水分阈值高于农作物 ( $R W C$ 为 $40 \% \sim 60 \%$ 之间), 这可能与苹果为木本植 物，而且是抗旱力中等的果树，相对于农作物有其特 殊的生物学习性和水分生理生态特点有关 (徐呈祥 等 2000$)$ 。

从生理生态的角度看, 光合作用与蒸腾作用分 别是 $\mathrm{CO}_{2}$ 和水汽分子通过叶片的内外交换过程, 其 主要通道是气孔。气孔运动控制着叶肉细胞水分、 $\mathrm{CO}_{2}$ 的交换及 $W U E$ 的高低(梁宗锁等,1999)。 
的交换同时受到气孔因素和叶肉因素的影响，因此， 气孔限制理论 (Farquhar \& Sharkey, 1982 ;许大全, 1997 沈允钢, 1998) 认为: 水分胁迫对光合作用的影 响分为气孔限制与非气孔限制两个方面。前者指水 分胁迫引起气孔关闭, $G_{s}$ 下降和 $\mathrm{CO}_{2}$ 供应受阻; 后 者指水分胁迫导致光合机构受到伤害, 叶肉细胞光 合能力下降, 包括叶肉细胞间隙气相空间和 $\mathrm{CO}_{2}$ 扩 散阻力增加、PS II 及光合磷酸化活性下降、RuBP 羧 化酶及 FBPaes 活性降低、RuBP 再生受阻等。并用 $C_{i}$ 和 $L_{s}$ 的变化方向作为判别依据和标准 :当 $P_{n}$ 和 $G_{s}$ 减小时, 若 $C_{i}$ 降低和 $L_{s}$ 升高, 为气孔限制; 若 $C_{i}$ 增高和 $L_{s}$ 下降, 为非气孔限制。从研究结果看: 在 轻度和中度水分胁迫下，气孔因素是光合作用下降 的主要原因, 而中度以上和严重水分胁迫下, 光合作 用主要受非气孔因素限制。植物受旱后, 随着水分 亏缺的加剧, 光合作用受抑制的主要原因都有从气 孔因素向非气孔因素转变的过程, 其转变时间因植 物种类及其抗旱能力, 水分胁迫程度及施加方式等 因素而异。但对不同植物种类而言, 导致这一转变 的确切的土壤水分临界值还不十分清楚(徐呈祥等, 2000)。本研究结果表明: 在田间土壤水分和自然干 旱条件下, 随着水分胁迫的加剧, 当 $R W C$ 大约小于 $48 \%$ ( SWC 小于 $10.0 \%$ ) 以后, 苹果叶片的 $P_{n}$ 和 $G_{s}$ 明显下降(图 1a，图 2a)， $L_{s}$ 明显下降和 $C_{i}$ 显著上升 (图 2b、c), 表明 $P_{n}$ 下降的主要原因已由气孔因素 转变为非气孔因素, 苹果叶片的光合机构受到破坏。 土壤水分进一步降低会使叶子变黄,甚至落叶, $W U E$ 和光合生产力严重下降。由此我们认为, $R W C$ 小于 $48 \%$ ( $S W C$ 等于 $10.0 \%$ ) 左右是半干旱黄土地 区苹果节水灌溉所允许的土壤水分最大亏缺程度。 这一土壤湿度与维持较高 WUE 的土壤水分下限 ( $R W C$ 为 50\%) 基本一致(图 1c)。

\section{参 考 文 献}

Berry, J. A. \& W. J. S. Dowton. 1982. Environment regulation of photosynthesis. In: Covind, J. ed. Photosynthesis. Vol. II . New York: Academic Press. $263 \sim 342$.

Cao, H. (曹慧), Y. P. Lan (兰彦平) \& F. Gao (高峰). 2000. Effects of water stress in soil on photosynthetic rate of spur apple trees. Journal of Shanxi Agricultural University (山西农业 大学学报), 20: 356 359. (in Chinese with English abstract) Chen, Y. M. (陈玉民), J. S. Sun (孙景生) \& J. F. Xiao (肖 俊夫). 1997. Studies on soil moisture controlling standard of water-saving irrigation. Irrigation and Drainage (灌溉排水), 16 (1) : $24 \sim 28$. (in Chinese with English abstract)

Farquhar, G. D. \& T. D. Sharkey. 1982. Stomatal conductance and photosynthesis. Annual Review of Plant Physiology, 33: 317 $\sim 345$.

Huang, Z. B. (黄占斌). 1998. Effect of limited water supply on water use efficiency of crops and its mechanism. Journal of Soil Erosion and Soil and Water Conservation (土壤侵蚀及水土保 持学报), 4(3): 92 93. (in Chinese with English abstract)

Huang, Z. B. (黄占斌) \& L. Shan (山仑). 1997. Diurnal change of water use efficiency of spring wheat and its physio-ecological bases. Chinese Journal of Applied Ecology (应用生态学 报), 8: $263 \sim 269$. (in Chinese with English abstract)

Jie, Y. L. (接玉玲), H. Q. Yang (杨洪强) \& M. G. Cui (崔 明刚). 2001. Relation between soil water content and water use efficiency of apple leaves. Chinese Journal of Applied Ecology (应用生态学报)，12: 387 390. (in Chinese with English abstract)

Jing, R. L. (景芯莲). 1999. Present situation and approach of study on crop drought resistance. Agricultural Research in the Arid Areas (干旱地区农业研究), 17(2)：79～85. (in Chinese with English abstract)

Li, H. S. (李合生). 2001. Modern plant physiology. Beijing: China Higher Education Press. 85 183. (in Chinese)

Li, Y. (李岩), D. Q. Li (李德全) \& H. C. Pan (潘海春). 1998. Study on the leaf cell turgor maintenance and its influence on leaf photosynthesis and growth of apple trees under drought stress. Journal of Fruit Science (果树科学), 15: 289 292 . (in Chinese with English abstract)

Liang, Z. S. (梁宗锁), S. Z. Kang (康绍忠) \& J. F. Gao (高 俊凤). 1999. Plant sensation and transduction of root signals and regulation of water use in dry soil condition. Agricultural Research in the Arid Areas (干旱地区农业研究), 17(2)：72 78. (in Chinese with English abstract)

Liu, F. J. (刘奉觉). 1997. Studies on comparison of measuring water-consumption for transpiration in poplar. Scientia Silvae Sinicae (林业科学), 33: $117 \sim 126$. (in Chinese with English abstract)

Liu, W. Z. (刘文兆). 1998. Dynamic interrelations of crop production, water consumption and water use efficiency. Journal of Natural Resources (自然资源学报), 13: 23 27. (in Chinese with English abstract)

Ma, Z. M. (马忠明). 1998. Studies on the relationship between crop and water under limited irrigation. Agricultural Research in the Arid Areas (干旱地区农业研究), 16(2)：75～79. (in Chinese with English abstract)

Qu, G. M. (曲桂敏), X. Shen (沈向 ) \& H. X. Wang (王鸿 霞). 2000. Effect of fruit on water use efficiency of apple trees under soil drought. Agricultural Research in the Arid Areas (干 旱地区农业研究), 18(2): 86 90. (in Chinese with English abstract)

Shan, L. (山仑) \& P. Y. Chen (陈培元). 1998. Physio-ecological bases of dryland agriculture. Beijing: Science Press. 1 17, $159 \sim 173$. (in Chinese)

Shan, L. (山仑) \& M. Xu (徐萌). 1991. Water-saving agriculture and its physio-ecological bases. Chinese Journal of Applied Ecology (应用生态学报), 2: $70 \sim 76$. (in Chinese with English abstract)

Shan, L. (山仑) . 1993. Theory and practice of dryland agriculture in Loess Plateau. Beijing: Science Press. $215 \sim 229$. (in Chinese) 
Shen, Y. G. (沈允钢). 1998. Dynamic photosynthesis. Beijing: Science Press. $130 \sim 132$. (in Chinese)

Wang, H. X. (王会肖) \& C. M. Liu (刘昌明)。2000. Advances in crop water use efficiency research. Advances Water Science (水科学进展), 11: 99 104. (in Chinese with English abstract)

Wang, K. Q. (王克勤) \& B. R. Wang (王斌瑞). 2002. The water use efficiency of Goldspur apple tree. Acta Ecologica Sinica (生态学报), 22: $723 \sim 728$. (in Chinese with English abstract)

Wang, W. Y. (王文元). 1988. Research on water consumption and irrigation of apple tree in northern China. Irrigation and Drainage (灌溉排水) , 7(3) : 15 20. (in Chinese with English abstract)

Wei， H. (魏虹)， K. Lin (林鬼) \& F. M. Li (李凤民). 2000. Effects of limited irrigation on the root development of spring wheat in semi-arid region. Acta Phytoecologica Sinica (植物生 态学报), 24: 106 110. (in Chinese with English abstract)

Xu, C. X. (徐呈祥) \& Y. P. Ma (马艳萍) . 2000. Studies on the reaction of apple to water stress and its water-saving irrigation. Journal of Nanjing Agricultural Technology College (南京
农专学报), 16(2): 15 22. (in Chinese with English abstract)

Xu, D. Q. (许大全). 1997. Some problems in stomatal limitation analysis of photosynthesis. Plant Physiology Communications (植 物生理学通讯), 33: 241 244. (in Chinese)

Yang, W. B. (杨文斌)，J. M. Ren (任建民) \& C. P. Jia (贾 翠萍) . 1997. Study on the relationship between physiological ecology of drought-resistance in Caragana korshinskii and soil water. Acta Ecologica Sinica (生态学报), 17: 239 244. (in Chinese with English abstract)

Zhang, L. X. (张立新) \& Z. L. Zhao (赵志励). 2001. Research on water management pattern in Fuji apple orchard under different annual precipitations on Weibei rainfed highland. Agricultural Research in the Arid Areas (干旱地区农业研究), 19 (1) : $26 \sim 32$. (in Chinese with English abstract)

Zhang, X. Y.(张喜英), D. Pei (裴冬) \& M. Z. You (由惁 正). 2000. Response of leaf water potential, photosynthesis and stomatal conductance to varying soil moisture in four crops: winter wheat, corn, sorghum and millet. Acta Phytoecologica Sinica (植物生态学报), 24: 280 283. (in Chinese with English abstract) 